\title{
DESEMPENHO E PRODUTIVIDADE DO MILHO EM FUNÇÃO DO CULTIVAR E DA ADUBAÇÃO DE COBERTURA EM REGIME DE SEQUEIRO NO CARIRI-CE
}

\author{
Maria Nágila Ferreira da Costa ${ }^{1 *}$, Wíctor Állyson Dias Rodrigues ${ }^{1}$, Toshik Iarley da Silva ${ }^{2}$, \\ Antonio Alves Pinto ${ }^{1}$, Felipe Thomaz da Camara ${ }^{3}$ \\ 1 Graduando(a) em Eng. Agronômica, Universidade Federal do Cariri, Crato - CE. *Email: \\ mmarianagila@gmail.com \\ ${ }^{2}$ Mestrando em Agronomia, Universidade Federal da Paraíba, Areias - Paraíba. \\ ${ }^{3}$ Docente da Universidade Federal do Cariri, Centro de Ciências Agrarias e da Biodiversidade, Crato - CE.
}

RESUMO: O trabalho visa avaliar respostas agronômicas do milho hibrido BR206 e variedade Al Piratininga em função do parcelamento da adubação nitrogenada em cobertura, em condição de sequeiro no Cariri cearense. O estudo foi conduzido no ano agrícola de 2015, no período de março a junho, na área experimental do Centro de Ciências Agrárias e da Biodiversidade (CCAB), da Universidade Federal do Cariri (UFCA), localizada na região do Cariri - CE. Foi utilizado o delineamento em blocos casualizados em esquema fatorial $2 \times 2$, com cinco repetições, totalizando 20 observações. O primeiro fator foi a cultivar de milho e o segundo foi a adubação nitrogenada em cobertura. As variáveis analisadas foram população final, número de espigas por planta, altura de plantas, a altura da primeira espiga, o perímetro do colmo, o comprimento da espiga, assim como a massa por planta, a massa por espiga e a massa verde total, como também a produtividade de grãos a 13\% de umidade, analisando o número de grãos por fileira e o número de grãos por espiga. Diante dos resultados obtidos, constatou-se que a variedade Al Piratininga se sobressai ao híbrido BR206, em relação à produtividade total sob as condições de sequeiro encontradas no Cariri cearense e a adubação nitrogenada em cobertura melhorou o desenvolvimento e produtividade do milho, porém o parcelamento não proporcionou acréscimos significativos.

Palavras-chave: Adaptação. Massa verde. Nutrientes.

\section{PERFORMANCE AND PRODUCTIVITY OF CORN IN FUNCTION OF THE CULTIVAR AND FERTILIZATION OF COVERAGE IN RAINFED CONDITIONS IN CARIRI-CE}

\begin{abstract}
The objective of this study was to evaluate the agronomic responses of the BR206 hybrid corn and the Al Piratininga variety due to the nitrogen fertilization in coverage, in the rainfed conditions of Cariri Cearense. The study was conducted in the agricultural year 2015, from March to June, in the experimental area of the Center for Agricultural Sciences and Biodiversity (CCAB), Federal University of Cariri (UFCA), located in the region of Cariri - CE. A randomized used was complete block design in a $2 \times 2$ factorial scheme, with five replications, totaling 20 observations. The first factor was the maize cultivar and the second was the nitrogen fertilization in coverage. The variables
\end{abstract}

Cultura Agronômica, Ilha Solteira, v.26, n.3, p.310-319, 2017 
analyzed were final population, number of ears per plant, height of plants, height of first ears, stem perimeter, spike length, as well as mass per plant, ears mass and total green mass, as well the grain yield at $13 \%$ moisture, analyzing the number of grains per row and the number of grains per ears. In view of the results obtained, it was verified that the variety $\mathrm{Al}$ Piratininga stands out to the hybrid BR206, in relation to the total productivity under the dry conditions found in the Cariri cearense and the nitrogen fertilization in coverage improved the development and productivity of the maize, did not provide significant additions.

Key words: Adaptation. Green mass. Nutrients.

\section{INTRODUÇÃO}

O Nordeste do Brasil é conhecido pelas restrições edafoclimáticas, porém o milho é cultivado em toda a região. Considerando este aspecto, existe diferentes sistemas de produção prevalecentes na região, infere-se que é de interesse o desenvolvimento de um programa de avaliação de variedades e híbridos, visando adequar cultivares de melhor adaptação e que sejam portadoras de atributos agronômicos desejáveis, buscando produzir milho verde ou silagem (VIEIRA et al., 2013).

A agricultura de sequeiro é amplamente praticada no Estado do Ceará, sendo uma atividade sujeita a altos riscos de perdas de safra devido à alta variabilidade, tanto temporal como espacial, das precipitações pluviométricas nas áreas semiáridas destas regiões de acordo com Andrade e Souza Filho (2006).

Meneguetti et al. (2002) relatam o uso de milhos crioulos ou variedades melhoradas como sendo uma técnica viável e econômica, por apresentar desempenho semelhante ou até mesmo superior em relação às variedades comerciais e híbridos. Todos os cultivares de milho possuem respostas diferenciadas em relação à adubação mineral, com o nitrogênio sendo um dos nutrientes que apresentam os efeitos mais expressivos no aumento da produção de grãos, que mesmo em cultivos de agricultura familiar, tem-se mostrado um dos engasgos para a produção, uma vez que é o nutriente exigido em maior quantidade e o que mais influência na produtividade do milho, assim como o que mais onera o custo de produção (COSTA et al., 2015).

Ao lado do nitrogênio, a deficiência do potássio $(\mathrm{K})$ limita a produtividade do milho (SILVA et al., 2005). As concentrações do nutriente $\mathrm{K}$ no solo, com valores inferiores ao recomendado, promove baixo crescimento do milho, assim como a fragilidade dos seus tecidos e maior sensibilidade à seca.

Desta forma, o presente trabalho visou avaliar respostas agronômicas do milho híbrido BR206 e variedade Al Piratininga em função da adubação nitrogenada em cobertura, em condição de sequeiro no Cariri cearense.

Cultura Agronômica, Ilha Solteira, v.26, n.3, p.310-319, 2017 


\section{MATERIAL E MÉTODOS}

O estudo foi conduzido no ano agrícola de 2015, no período de março a junho, na área experimental do Centro de Ciências Agrárias e da Biodiversidade (CCAB), campus CratoCE, da Universidade Federal do Cariri (UFCA), localizada na região do Cariri - CE, situado em um solo classificado como Argissolo Vermelho Amarelo distrófico abrúptico, conforme classificação do mapa de solos da FUNCEME (2012), de relevo suave ondulado e textura da camada superficial do solo classificada como franco-arenosa. O clima da região, segundo a classificação de Köeppen é Aw, caracterizado como tropical úmido, com inverno característico seco e estação chuvosa de novembro a abril, com estação seca no inverno de maio a outubro.

Foi utilizado o delineamento em blocos casualizados em esquema fatorial $2 \times 2$, com cinco repetições, totalizando 20 observações. O primeiro fator estudado foram dois cultivares de milho ( 1 - Híbrido BR206 e 2 - Variedade Al Piratininga) e o segundo dois níveis de adubação nitrogenada em cobertura (1 - Uma cobertura; 2 - Duas coberturas). Cada parcela experimental continha cinco fileiras de milho espaçadas a $0,9 \mathrm{~m}$, com cinco metros de comprimento $\left(22,5 \mathrm{~m}^{2}\right)$.

O preparo do solo foi realizado por meio de duas gradagens com grade leve, promovendo a mobilização do solo até a profundidade de $15 \mathrm{~cm}$.

A semeadura e a adubação de fundação foram realizadas em uma mesma operação utilizando uma semeadora adubadora de tração animal da marca Knapik, dotada de disco de corte a frente do sistema de distribuição do adubo, que é realizada por haste sulcadora (facão). Em seguida tem o sistema de abertura de sulcos para a deposição das sementes por disco duplo defasado, com sistema dosador de sementes por discos horizontais regulada para depositar 6 sementes por metro, ou seja, uma semente a cada $16,7 \mathrm{~cm}$, com um espaçamento entre fileiras de $0,9 \mathrm{~m}$, totalizando 66.666 sementes depositadas por hectare.

Para a adubação de fundação a dose utilizada foi igual para todos os tratamentos, sendo obtida com base na análise de solo conforme recomendação da Embrapa para a cultura do milho (EMBRAPA, 2008). A adubação foi realizada por meio de adubos simples, sendo utilizado na semeadura $100 \mathrm{~kg} \mathrm{ha}^{-1}$ de sulfato de amônio, $500 \mathrm{~kg} \mathrm{ha}^{-1}$ de superfosfato simples e $60 \mathrm{~kg} \mathrm{ha}^{-1}$ de cloreto de potássio.

Para a adubação em cobertura foi recomendado $60 \mathrm{~kg} \mathrm{ha}^{-1}$ de cloreto de potássio e $500 \mathrm{~kg} \mathrm{ha}^{-1}$ de sulfato de amônio, com o cloreto de potássio sendo aplicado todo juntamente com o nitrogênio na primeira cobertura, enquanto que o nitrogênio foi fator de estudo em dois níveis (1 e 2), onde 1 - a aplicação da dose total recomendada entre os estádios V5 e V6; e 2 - parcelamento da dose recomendada em duas aplicações com quantidades iguais , a primeira entre V3 e V4 (50\%) e a segunda entre V6 e V7 (50\%).

As variáveis analisadas foram a população final (PF), o número de espigas por planta (NEP), a altura de plantas (AP), a altura da primeira espiga (AE), o perímetro do colmo 
(PC), o comprimento da espiga (CE), a massa verde por planta (MPP), a massa verde de plantas por hectare (MPV), a massa verde por espiga (MPE), a massa das espigas verdes por hectare (MEV), a massa verde total (MVT), o número de fileiras de grãos por espiga (NFGE), o número de grãos por fileira (NGF), o número de grãos por espiga (NGE) e a produtividade de grãos com $13 \%$ de umidade $(\mathrm{P})$.

Estas medidas foram obtidas por meio da colheita das plantas contidas em três fileiras centrais, com dois metros de comprimento $\left(11,7 \mathrm{~m}^{2}\right)$. A quantidade colhida era pesada em balança de precisão semi-analítica e os resultados extrapolados para hectares.

Todos os dados foram submetidos à análise de variância e ao teste de comparação de médias de Tukey a 5\% de probabilidade, utilizando-se o programa estatístico SISVAR 5.3 (FERREIRA, 2011).

\section{RESULTADOS E DISCUSSÃO}

Pode-se verificar na Tabela 1 que não ocorreram interações significativas para todas as variáveis analisadas, fato que permite a análise direta das médias obtidas para cada nível dos fatores separadamente. Para a altura da primeira espiga houve diferença significativa a $5 \%$ de probabilidade pelo teste $\mathrm{F}$ em função da adubação de cobertura, onde foram observados maiores valores com o uso de adubação nitrogenada em uma única cobertura, com dose total, sendo que os cultivares de milho avaliados obtiveram valores semelhantes $(\mathrm{p}>0,05)$.

Esses valores são contrários aos dados estatísticos encontrados na pesquisa de Duete et al. (2008), o qual obtiveram maior altura de planta e altura da primeira espiga com a aplicação parcelada de nitrogênio

Os resultados de altura da primeira espiga corroboram com os obtidos por Custódio et al. (2003), que verificaram que a altura de inserção da espiga nas plantas foi maior naquelas cultivares mais adaptadas ao ambiente.

Com relação ao número de espigas por planta e perímetro do colmo, nota-se que não foi influenciado pelos cultivares de milho utilizados e nem pela adubação de cobertura (Tabela 1). Os valores da forma de adubação não se enquadram na explicação de Portela et al. (2016) onde afirmam que parcelamento do nitrogênio promove maiores rentabilidades de espigas comerciais em virtude da minimização das perdas por lixiviação, o que promove melhor aproveitamento do elemento pela planta.

Já o comprimento da espiga foi influenciado significativamente $(\mathrm{p}<0,01)$ para o fator milho, a variedade mostrou-se estatisticamente melhor que o híbrido através do teste de Tukey, promovendo espigas com maior comprimento.

A análise estatística revela que o uso de adubação em cobertura aplicada de forma parcelada ou não, foi irrelevante estatisticamente para a massa por planta. Meira et al. (2009) observaram efeitos diferentes quando o nitrogênio foi fornecido em fracionamento

Cultura Agronômica, Ilha Solteira, v.26, n.3, p.310-319, 2017 
de doses por ocasião da cobertura, havendo $\mathrm{N}$ disponível na solução do solo no período em que a planta requer maior quantidade e como consequência os maiores incrementos na produção de grãos, devido o comprimento de espiga ser maior.

Tabela 1. Síntese da análise de variância e do teste de médias para a população final (PF), número de espigas por planta (NEP), a altura de plantas (AP), a altura da primeira espiga (AE), o perímetro do colmo (PC), o comprimento da espiga $(\mathrm{CE})$, e a massa por planta (MPP).

\begin{tabular}{|c|c|c|c|c|c|c|c|}
\hline Tratamentos & $\begin{array}{c}\text { PF } \\
\text { Plantas ha' }\end{array}$ & $\begin{array}{c}\text { NEP } \\
\text { Unidade }\end{array}$ & AP & $\begin{array}{c}\mathrm{AE} \\
---\mathbf{c m}\end{array}$ & PC & CE & $\begin{array}{c}\text { MPP } \\
\text { g planta-1 }^{-1}\end{array}$ \\
\hline \multicolumn{8}{|l|}{ Milho (M) } \\
\hline Hibrido & 51667 & 1,0 & 119,5 & $33,7 \mathrm{~b}$ & 5,3 & $23,0 \mathrm{~b}$ & 191,4 \\
\hline Variedade & 53333 & 1,0 & 127,2 & $54,3 \mathrm{a}$ & 5,4 & $25,8 \mathrm{a}$ & 163,5 \\
\hline \multicolumn{8}{|l|}{ Adubação (A) } \\
\hline Uma cobertura & 53333 & 1,0 & 124,4 & 48,7 a & 5,5 & 24,1 & 172 \\
\hline Duas coberturas & 51667 & 1,0 & 122,3 & $39,3 \mathrm{~b}$ & 5,3 & 24,7 & 182,9 \\
\hline \multicolumn{8}{|l|}{ TESTE F } \\
\hline $\mathbf{M}$ & $0,33^{\mathrm{NS}}$ & $1,00^{\mathrm{NS}}$ & $1,93^{\mathrm{NS}}$ & $25,85 * *$ & $0,31^{\mathrm{NS}}$ & $8,70 *$ & $2,25^{\mathrm{NS}}$ \\
\hline $\mathbf{A}$ & $0,33^{\mathrm{NS}}$ & $1,00^{\mathrm{NS}}$ & $0,13^{\mathrm{NS}}$ & $5,27 *$ & $0,41^{\mathrm{NS}}$ & $0,47^{\mathrm{NS}}$ & $0,34^{\mathrm{NS}}$ \\
\hline $\mathbf{M} * \mathbf{A}$ & $0,33^{\mathrm{NS}}$ & $1,00^{\mathrm{NS}}$ & $1,86^{\mathrm{NS}}$ & $2,58^{\mathrm{NS}}$ & $0,13^{\mathrm{NS}}$ & $0,15^{\mathrm{NS}}$ & $0,73^{\mathrm{NS}}$ \\
\hline CV\% & 9,52 & 0,00 & 7,77 & 16,00 & 9,24 & 6,58 & 18,17 \\
\hline
\end{tabular}

Médias seguidas pela mesma letra minúscula na coluna, não diferem entre si pelo teste de Tukey a 5\% de probabilidade. **: significativo $(\mathrm{P}<0,01)$; *: significativo $(\mathrm{P}<0,05)$; NS: não significativo; $\mathrm{CV} \%$ : coeficiente de variação.

Na Tabela 2 verifica-se que não ocorreram interações significativas entre os fatores avaliados, e que para o cultivar não ocorreram diferenças significativas, bem como para o fator adubação, em todas as variáveis.

Com relação às médias (Tabela 2), Com relação às variáveis MPV, MPE, MEV e MVT, nota-se que o uso da adubação nitrogenada em cobertura com dose única teve o mesmo comportamento da adubação nitrogenada parcelada em duas aplicações, evidenciando que a aplicação em dose única é mais vantajosa em função da redução nos custos devido à eliminação de uma nova aplicação.

Podendo ser explicado devido à irregularidade das chuvas no período experimental, provocando o não aproveitamento correto das doses do nitrogênio, por conta da falta de água no solo para promover a mineralização, trazendo perdas do nitrogênio para a atmosfera e por lixiviação, fazendo com que a resposta da planta seja semelhante a utilização de apenas uma dose.

Queiroz et al. (2011) explicam que esse nutriente se caracteriza por possuir um dos maiores índices de perdas, as quais podem ocorrer por lixiviação, escorrimento superficial, erosão, volatilização de amônia e desnitrificação. O maior ou menor índice de perda pode ser contornado pela forma de aplicação, manejo e fonte do nutriente a ser utilizada.

Cultura Agronômica, Ilha Solteira, v.26, n.3, p.310-319, 2017 
Tabela 2. Síntese da análise de variância e do teste de médias para massa verde de plantas (MPV), massa por espiga (MPE); massa das espigas verdes por hectare (MEV); massa verde total (MVT)

\begin{tabular}{ccccc}
\hline Tratamentos & $\begin{array}{c}\text { MPV } \\
\text { kg ha }^{-1}\end{array}$ & $\begin{array}{c}\text { MPE } \\
\text { g espiga }^{-1}\end{array}$ & $\begin{array}{c}\text { MEV } \\
\mathbf{k g ~ h a}^{-1}\end{array}$ & $\begin{array}{c}\text { MVT } \\
\mathbf{k g ~ h a}^{-1}\end{array}$ \\
\hline $\begin{array}{c}\text { Milho (M) } \\
\text { Hibrido }\end{array}$ & 9869 & 135,6 & 7008 & 16878 \\
Variedade & 8703 & 122,9 & 6522 & 15226 \\
\hline Adubação (A) & & & & \\
Uma cobertura & 9190 & 141,0 & 7513 & 16703 \\
$\begin{array}{c}\text { Duas coberturas } \\
\text { TESTE F }\end{array}$ & 9382 & 117,6 & 6018 & 15400 \\
\hline M & $1,31^{\mathrm{NS}}$ & $0,79^{\mathrm{NS}}$ & $0,44^{\mathrm{NS}}$ & $0,95^{\mathrm{NS}}$ \\
$\mathbf{A}$ & $0,03^{\mathrm{NS}}$ & $2,67^{\mathrm{NS}}$ & $4,18^{\mathrm{NS}}$ & $0,59^{\mathrm{NS}}$ \\
$\mathbf{M}^{\mathrm{N}} \mathbf{A}$ & $0,30^{\mathrm{NS}}$ & $0,34^{\mathrm{NS}}$ & $0,16^{\mathrm{NS}}$ & $0,25^{\mathrm{NS}}$ \\
\hline CV\% & 19,01 & 19,16 & 18,71 & 18,27 \\
\hline
\end{tabular}

Médias seguidas pela mesma letra minúscula na coluna, não diferem entre si pelo teste de Tukey a 5\% de probabilidade. **: significativo $(\mathrm{P}<0,01)$; *: significativo ( $\mathrm{P}<0,05)$; NS: não significativo; $\mathrm{CV} \%$ : coeficiente de variação.

Scapim et al. (2010), analisando produção de massa verde, constataram que há efeitos significativos na interação entre genótipo e ambiente, demonstrando que a resposta dos genótipos se diferem quando trabalhado com manejo e ambientes iguais. Estes resultados não condizem aos encontrados na presente pesquisa, onde mostram que as médias para a massa verde de plantas, massa das espigas verdes e massa verde total não foram diferentes estatisticamente em relação ao tipo genético do material.

Os valores das variáveis número de fileiras de grãos por espiga, número de grãos por fileira e por espiga e produtividade estão dispostos na Tabela 3, onde não se verificou a ocorrência de interações significativas, porém apenas número de fileira de grãos por espiga e produtividade apresentaram diferença significativa $(\mathrm{p}<0,01)$ para o fator milho, sendo que o NFGE teve diferença estatística para ambos fatores.

O milho variedade obteve os melhores resultados para todas as variáveis, exceto o número de grãos por fileira, com destaque para a produtividade superior à obtida pelo milho híbrido. Araújo et al. (2013) puderam inferir que as variedades crioulas foram capazes de responder positivamente à aplicação de tecnologia no manejo da cultura, superior aos híbridos. Os mesmos testaram variedades crioulas e cultivares híbridas comerciais em diferentes níveis tecnológicos de cultivo.

Concordando com Machado et al. (2003) que também observaram melhores resultados para as variedades crioulas de milho, quando cultivadas em solo com baixo teor de N. O genótipo de espécies com maior variabilidade tendem a se sobressair em relação às 
cultivares híbridas comerciais, isso ocorre segundo Eicholz et al. (2013) em virtude da base genética ampla, são capazes de responder melhor aos estresses abióticos e bióticos.

Tabela 3. Síntese da análise de variância e do teste de médias para o número de fileiras de grãos por espiga (NFGE), número de grãos por fileira (NGF); número de grãos por espiga (NGE) e produtividade (P).

\begin{tabular}{lcccc}
\hline Tratamentos & $\begin{array}{c}\text { NFGE } \\
\text { Unidade }\end{array}$ & $\begin{array}{c}\text { NGF } \\
\text { Unidade }\end{array}$ & $\begin{array}{c}\text { NGE } \\
\text { Unidade }\end{array}$ & $\begin{array}{c}\text { P } \\
\text { kg ha }^{-1}\end{array}$ \\
\hline Milho (M) & $10,9 \mathrm{~b}$ & 19,1 & $224 \mathrm{~b}$ & $2580 \mathrm{~b}$ \\
Hibrido & $14,3 \mathrm{a}$ & 23,6 & $340 \mathrm{a}$ & $4108 \mathrm{a}$ \\
Variedade & & & & \\
\hline Adubação (A) & $13,5 \mathrm{a}$ & 24,2 & 294 & 3597 \\
Uma cobertura & $11,7 \mathrm{~b}$ & 18,4 & 270 & 3091 \\
Duas coberturas & & & & \\
\hline TESTE F & $130,22^{* *}$ & $2,81^{\mathrm{NS}}$ & $9,57^{*}$ & $8,33^{* *}$ \\
$\mathbf{M}$ & $34,73^{* *}$ & $4,62^{\mathrm{NS}}$ & $0,41^{\mathrm{NS}}$ & $0,91^{\mathrm{NS}}$ \\
$\mathbf{A}$ & $3,90^{\mathrm{NS}}$ & $2,12^{\mathrm{NS}}$ & $0,56^{\mathrm{NS}}$ & $0,22^{\mathrm{NS}}$ \\
\hline $\mathbf{M}^{*} \mathbf{A}$ & 4,21 & 21,89 & 23,16 & 27,43 \\
\hline CV\% & & &
\end{tabular}

Médias seguidas pela mesma letra minúscula na coluna, não diferem entre si pelo teste de Tukey a 5\% de probabilidade. ${ }^{* *}$ : significativo $(\mathrm{P}<0,01)$; *: significativo $(\mathrm{P}<0,05)$; NS: não significativo; $\mathrm{CV} \%$ : coeficiente de variação.

O uso de adubação nitrogenada em cobertura não parcelada elevou os valores de número de fileiras de grãos por espiga, porém, com relação ao parcelamento, o mesmo não surtiu efeito significativo, dados que discordam do estudo de Kaneko et al. (2013) que obtiveram maiores produtividades para o parcelamento do nitrogênio, pois os grânulos do adubo nitrogenado em contato com o solo proporcionam reações químicas que alcalinizam ao redor de seu meio, possibilitando perdas por volatilização do adubo, principalmente em aplicações de cobertura.

Os dados de produtividade condiz com os de Bastos et al. (2008), mostrando que não obteveram diferença significativa entre a aplicação total e o parcelamento do nitrogênio sobre a produtividade.

Os dados de produtividades alcançados no presente estudo foram superiores à média do estado do Ceará e da região Nordeste no ano agrícola 2014/15, que segundo a Companhia Nacional de Abastecimento foi de 336 e $2049 \mathrm{~kg} \mathrm{ha}^{-1}$, respectivamente (CONAB, 2015), sendo que a variedade obteve valores próximos à média nacional no referido ano que foi de $3586 \mathrm{~kg} \mathrm{ha}^{-1}$ segundo o mesmo levantamento. 


\section{CONCLUSÃO}

O híbrido BR206, pelo seu rendimento no ambiente de sequeiro, não mostra-se como opção viável para os agricultores do Cariri cearense em comparação com a variedade $\mathrm{AL}$ Piratininga que teve desempenho com altos rendimentos de milho verde e de grãos, com tendências de adaptação aos ambientes desfavoráveis e consistir em alternativa indicada para os sistemas de produção dos pequenos e médios produtores rurais em regime de sequeiro.

O uso de adubação nitrogenada em cobertura em uma única aplicação, favorece o desenvolvimento e a produtividade do milho, com o parcelamento não ocasionando ganhos significativos de produtividade de milho verde e de grãos, sendo indicado o uso de aplicação da dose total do nitrogênio em cobertura entre os estádios V5 e V6.

\section{AGRADECIMENTOS}

Ao Programa de Educação Tutorial (PET) do curso de Agronomia da Universidade Federal do Cariri (UFCA) pela bolsa concedida e a oportunidade de desenvolver a referida pesquisa.

\section{REFERÊNCIAS BIBLIOGRÁFICAS}

ANDRADE, F. C. M.; SOUZA FILHO, F. A. Estimativa de ganho potencial com a previsão climática nos plantios de feijão e milho no estado do ceará. Área temática: agricultura e pecuária. p. 1-26, 2006. Disponível em: https://www.researchgate.net/profile/Fernando_Andrade16/publication/275656472_Estimati va_de_Ganho_Potencial_com_a_Previsao_Climatica_nos_Plantios_de_Feijao_e_Milho_no _Estado_do_Ceara/links/554394c70cf234bdb21bd264.pdf . Acesso em: 17 jul. 2016.

ARAÚJO, A. V.; BRANDÃO JUNIOR, D. S.; FERREIRA, I. C. P. V.; COSTA, C. A.; PORTO, B. B. A. Desempenho agronômico de variedades crioulas e híbridos de milho cultivados em diferentes sistemas de manejo. Revista Ciência Agronômica, Fortaleza, v. 44, n. 4, p.885-892, 2013.

BASTOS, E. A. CARDOSO, M. J.; MELO, F. B.; RIBEIRO, V. Q.; ANDRADE JÚNIOR, A. S. Doses e formas de parcelamento de nitrogênio para a produção de milho sob plantio direto. Revista Ciência Agronômica, Fortaleza, v. 39, n. 2, p.275-280, 2008.

COMPANHIA NACIONAL DE ABASTECIMENTO- CONAB. Acompanhamento da safra brasileira de grãos. Brasília, v. 3, n. 3, p. 19, 2015. Disponível em: http://www.conab.gov.br/OlalaCMS/uploads/arquivos/15_12_11_11_02_58_boletim_graos _dezembro_2015.pdf. Acesso em: 17 jul. 2016. 
COSTA, F. R; DAMASO, L. F; MENDES, R. C; MARQUES, D. D; RODRIGUES; F. Desempenho de híbridos de milho para consumo in natura em diferentes doses de nitrogênio. Revista Científica, Jaboticabal, v. 43, n. 2, p.109-116, 2015.

CRUZ, S. C. S.; PEREIRA, F. R. S.; SANTOS, J. R.; ALBUQUERQUE, A. W.; PEREIRA, R. G. Adubação nitrogenada para o milho cultivado em sistema plantio direto, no Estado de Alagoas. Revista Brasileira Engenharia Agrícola e Ambiental, Campina Grande, v. 12, n. 1, p.62-68, 2008.

CUSTÓDIO, D. P.; PASQUALETTO, A.; OLIVEIRA, I. P. Comportamento de cultivares de milho (Zea mays) e sistemas de cultivo. Revista Estudos, Goiânia, v. 30, n. 8, p.1793$1803,2003$.

DUETE, R. R. C.; MURAOKA, T.; SILVA, E. C.; TRIVELIN, P. C.O.; AMBROSANO, E. J. Manejo da adubação nitrogenada e utilização do nitrogênio $(15 \mathrm{~N})$ pelo milho em Latossolo Vermelho. Revista Brasileira de Ciência do Solo, Votuporanga, v. 32, n. 1, p.161-171, 2008.

EICHOLZ, E. D.; EICHOLZ, M.; FONSECA, E.; SILVA, S. D. A. Avaliação agronômica de variedades de milho no sul do RS. In: REUNIÃO TÉCNICA ANUAL DO MILHO, 58., 2013, Pelotas - $\quad$ RS. Anais... Disponível em: http://www.alice.cnptia.embrapa.br/bitstream/doc/981500/1/EbersonEicholz.pdf. Acesso em: 10 ago. 2016.

EMPRESA BRASILEIRA DE PESQUISA AGROPECUÁRIA (EMBRAPA). Manejo da adubação nitrogenada na cultura do milho: Nutrição e Adubação, 2008. Disponível em: http://www.cnpms.embrapa.br/publicacoes/publica/2007/circular/Circ_96.pdf . Acesso em: 15 ago. 2016.

FERREIRA, D. F. Sisvar: a computer statistical analysis system. Ciência e Agrotecnologia, Lavras, v. 35, n. 6, p.1039-1042, 2011.

FUNDAÇÃO CEARENSE DE METEOROLOGIA E RECURSOS HÍDRICOS FUNCEME. Levantamento de reconhecimento de média intensidade dos solos da Mesoregião do Sul Cearense. Fortaleza, 2012. Disponível em: ftp://ftp.funceme.br/Meio_ambiente/ZACE/tmp/folha/folhas.10.pdf . Acesso em: 10 ago. 2016.

KANEKO, F. H.; LEAL, A. J. F.; ANSELMO, J. L.; BUZETTI, S.; TOSTA, F. S. Fontes e manejos da adubação nitrogenada em algodoeiro. Pesquisa Agropecuária Tropical, Goiânia, v. 43, n. 1, p.57-63, 2013.

MACHADO, A. T.; MACHADO, C. T. T.; MIRANDA, G. V.; COELHO, C. H. M.; GUIMARÃES, L. J. M. Resposta de variedades de milho a níveis e fontes de nitrogênio. Planaltina: Embrapa Cerrados, 2003. 27 p. (Boletim de Pesquisa e Desenvolvimento, 93).

Cultura Agronômica, Ilha Solteira, v.26, n.3, p.310-319, 2017 
MEIRA, F. A.; BUZETTI, S.; ANDREOTTI, M.; ARF, O.; SÁ, M. E.; ANDRADE, J. A. C. Fontes e modos de aplicação do nitrogênio na cultura do milho irrigado. Semina: Ciências Agrárias, Londrina, v. 30, n. 2, p.275-284, 2009.

MENEGUETTI, G. A.; GIRARDI, J. L.; REGINATTO, J. C. Milho crioulo: tecnologia viável e sustentável. Agroecologia e Desenvolvimento Rural Sustentável, Porto Alegre, v. 3, n. 1, p.12-17, 2002.

PORTELA, M. G. T.; ARAÚJO, R. L.; BARBOSA, R. P.; ROCHA, D. R. Características agronômicas do milho submetido a fontes e parcelamento de nitrogênio em cobertura. Brazilian journal of biosystems engineering, Teresina, v. 10, n. 3, p.248-258, 2016.

QUEIROZ, A. M.; SOUZA, C. H. E. de; MACHADO, V. J.; LANA, R. M. Q.; KORNDORFER, G.H.; SILVA, A. de A. Avaliação de diferentes fontes e doses de nitrogênio na adubação da cultura do milho (Zea mays L.). Revista Brasileira de Milho e Sorgo, v.10, n.3, p. 257-266, 2011.

SCAPIM, C. A.; PACHECO, C. A. P.; AMARAL JÚNIOR, A. T.; VIEIRA, R. A.; PINTO, R. J. B.; CONRADO, T. V. Correlations between the stability and adaptability statistics of popcorn cultivars. Euphytica, Filadélfia, v. 174, n. 2, p.209-218, 2010.

SILVA, E. C.; BUZETTI S.; GUIMARÃES, G. L.; LAZARINI, E.; SÁ, M. E. Doses e épocas de aplicação de nitrogênio na cultura do milho em plantio direto sobre Latossolo Vermelho. Revista Brasileira de Ciência do Solo, Viçosa, v. 29, n. 3, p.353-362, 2005.

VIEIRA, V. C.; MARTIN, T. N.; MENEZES, L. F. G.; ASSMANN, T.; ORTIZ, S.; BERTONCELLI, P.; PIRAN FILHO, F. A.; SCHIMITZ, T. H. Caracterização bromatológica e agronômica de genótipos de milho para produção de silagem. Arquivo Brasileiro de Medicina Veterinária e Zootecnia, Belo Horizonte, v. 65, n. 3, p.847-856, 2013.

Cultura Agronômica, Ilha Solteira, v.26, n.3, p.310-319, 2017 